\title{
Using MSG to monitor the evolution of severe convective storms over East Mediterranean Sea and Israel, and its response to aerosol loading
}

\author{
I. M. Lensky and S. Shiff \\ Department of Geography and Environment, Bar-Ilan University, Ramt-Gan, Israel \\ Received: 2 March 2007 - Revised: 30 July 2007 - Accepted: 6 August 2007 - Published: 13 August 2007
}

\begin{abstract}
Convective storms over East Mediterranean sea and Israel were tracked by METEOSAT Second Generation (MSG). The MSG data was used to retrieve time series of the precipitation formation processes in the clouds, the temperature of onset of precipitation, and an indication to aerosol loading over the sea. Strong correlation was found between the aerosol loading and the depth above cloud base required for the initialization of effective precipitation processes (indicated by the effective radius $=15 \mu \mathrm{m}$ threshold). It seems from the data presented here that the clouds' response to the aerosol loading is very short.
\end{abstract}

\section{Introduction}

In March and April 2006, toward the end of the rain season in Israel, few very severe rain events occurred. Some of the events were accompanied with dust (9 March , 4 April), other produced floods ( 2 April) and even one tornado was recorded (4 April). These events will be analyzed here using a technique that Rosenfeld and Lensky introduced in 1998. In the Rosenfeld Lensky technique (RLT), vertical profiles of the cloud particles' effective radius $\left(r_{e}\right)$ are analyzed to gain insights into precipitation forming processes. Rosenfeld and Lensky (1998) used Advanced Very High Resolution Radiometer (AVHRR) data on the polar orbiting NOAA satellites for their study. Later the RLT was applied to other sensors on polar orbiting satellites (VIRS on TRMM, GLI on ADEOS II, MODIS on Terra and Aqua), and was used in many studies to assess the impact of different aerosols on clouds and precipitation. (Rosenfeld, 1999, 2000; Rosenfeld et al., 2001, 2002, 2004; Rosenfeld and Woodley, 2001, 2003; Ramanathan et al., 2001; Rudich et al., 2002, 2003;

Correspondence to: I. M. Lensky

(lenskyi@mail.biu.ac.il)
Tupper et al., 2004; Williams et al., 2002; Woodley et al., 2000).

Lensky and Drori (2007) followed the RLT approach and defined the temperature of onset of precipitation $\left(T_{15}\right)$, as the temperature where the median $r_{e}$ exceeds a precipitation threshold of $15 \mu \mathrm{m}$ (Lensky and Rosenfeld, 1997), and $D_{15}$ as the temperature difference (depth) between $T_{15}$ and the cloud base temperature $\left(T_{\text {base }}\right)$.

In this paper we use data from the European geostationary satellite METEOSAT Second Generation (MSG) to retrieve time series of the RLT microphysical zones, $D_{15}$, and an indication to the aerosol loading over the sea.

In the next section the methodology of the cloud characterization will be described, followed by the case studies. Summary and conclusions will close this paper.

\section{Methodology}

The retrieval of precipitation formation processes is done by using microphysical zones from the RLT. The RLT uses $r_{e}$ and cloud top temperature $(T)$ of all the cloudy pixels in a predefined area as input. One of the outputs of the RLT is the highest and lowest temperatures of the following five microphysical zones: the diffusional growth zone, coalescence growth zone, rain out zone, mixed phase zone and glaciated zone. These microphysical zones and $T_{15}$ are schematically shown in Fig. 1.

The RLT is based on two assumptions:

(a) The evolution of $r_{e}$ with height (or $T$ ), observed by the satellite at a given time (snapshot), for a cloud ensemble over an area, is similar to the $T-r_{e}$ time evolution of a given cloud at one location. This assumption of exchangeability between the time and space domains is called the ergodicity assumption (see Fig. 2a).

Published by Copernicus Publications on behalf of the European Geosciences Union. 


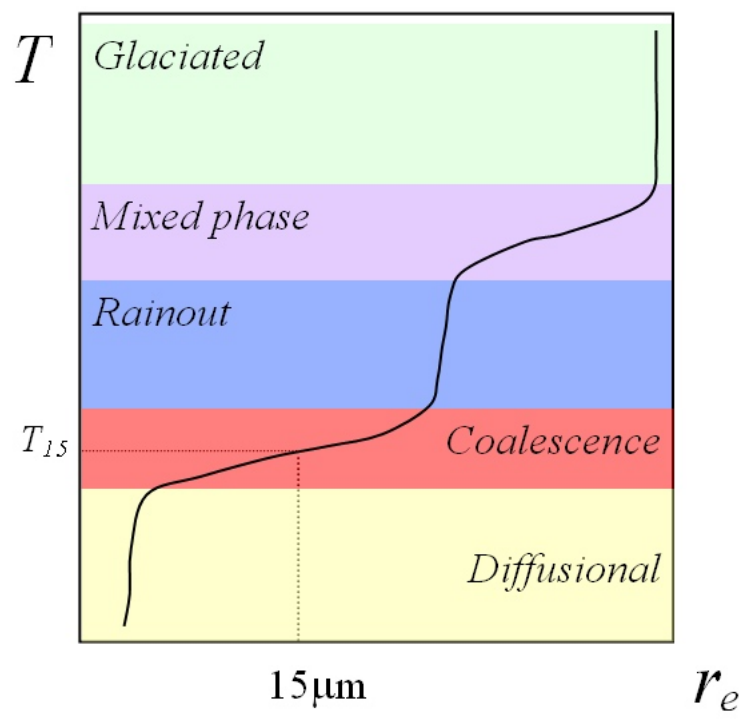

Fig. 1. Schematic representation of the five microphysical zones: diffusional, coalescence, rain out, mix phase and glaciated; and the temperature of onset of precipitation $\left(T_{15}\right)$.

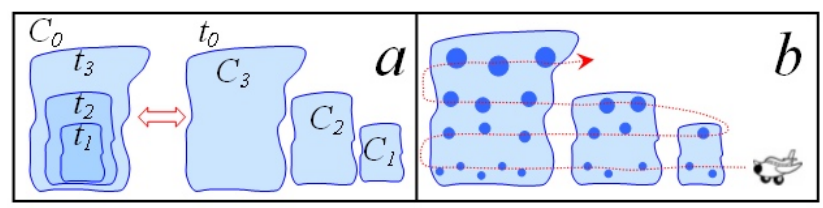

Fig. 2. Schematic representation of the two assumptions underlying the RLT. (a) the ergodicity assumption (exchangeability between the time and space domains) says that the $T-r_{e}$ observed by the satellite at a given time $\left(t_{0}\right)$ for a cloud ensemble $\left(C_{1} C_{2} C_{3}\right)$ over an area, is similar to the time evolution $\left(t_{1} t_{2} t_{3}\right)$ of the $T-r_{e}$ of a given cloud $\left(C_{0}\right)$, at one location. (b) the $r_{e}$ near cloud top is similar to that well within the cloud at the same height as long as precipitation does not fall through that cloud volume.

(b) The $r_{e}$ near cloud top $\left(T_{1}\right)$ of one cloud in a cloud cluster, is similar to the $r_{e}$ of any other cloud in the same cloud cluster, at the same height (where $T_{1}$ is well within the other clouds) as long as precipitation does not fall through that cloud volume (see Fig. 2b), and that all the clouds in the cloud cluster, are in the same environment in terms of the ambient air's dynamic, thermodynamic and aerosol loading. Different clouds in this cloud cluster should have more or less the same $\mathrm{CCN}$. This assumption may brake in the vicinity of a point source of aerosols such as power plant (Rosenfeld, 2000), or if the analyzed area is too large. In that case a more careful treatment of the $T-r_{e}$ plot will be needed (i.e. the use of different percentiles of the $r_{e}$ for different clouds).

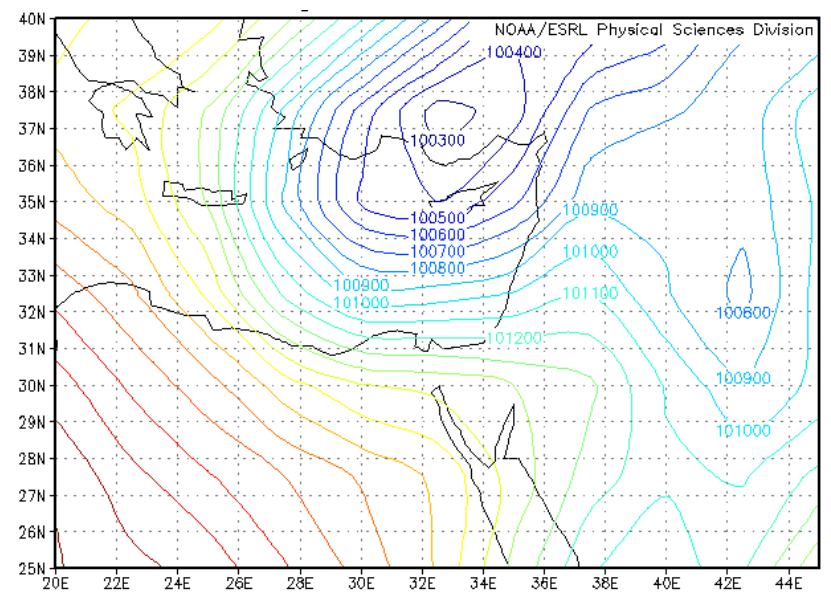

Fig. 3. Sea level pressure (in Pascal) for 9 March 2006, 06:00 GMT, based on the NCEP-NCAR CDAS-1 archive (Kalnay et al., 1996; Kistler et al., 2001).

The second assumption was verified using in situ aircraft measurements (Rosenfeld and Lensky, 1998; Freud et al., 2005). To address the ergodicity assumption, Lensky and Rosenfeld (2006) used rapid scan data (three minutes interval) of the Spinning Enhanced Visible and InfraRed Imager (SEVIRI) on board the MSG satellite (Schmetz et al., 2002). One outcome of that study was a tool named CAPSAT: Clouds, Aerosols, and Precipitation Satellite Analysis Tool (Lensky and Rosenfeld, $2007^{1}$ ). In this paper we used CAPSAT to analyze the MSG data. In each area and time step (see Sect. 3) we looked for the five microphysical zones defined in the RLT, and $T_{15}$. As an indication for the aerosol loading over the sea we looked for the smallest cloud free visible $(0.6 \mu \mathrm{m})$ reflectance in area 1 .

\section{The case studies}

In this study we use MSG SEVIRI data. Fifteen minutes interval data, from 06:00 to 14:00 GMT from three cases of sever weather in 2006: 9 March, 2 April and 4 April were used to monitor convective clouds over East Mediterranean Sea (area 1) and Israel (area 2).

In the first case study from 9 March 2006, a highly developed large scale cyclonic system approached Israel in the early morning (see Fig. 3), with a dust storm developing over South East Mediterranean. Figure 4 shows clouds and dust interacting in areas 1 and 2 at 06:00 GMT (a); 08:00 GMT (b); 11:00 GMT (c); and 13:00 GMT (d). In this color scheme, clouds are colored in orange and red, and dust is colored in pink. Strong dust storm is developing in the northeast corner of area 2 in panel $b$, and intensifies in panels $c$ and

\footnotetext{
${ }^{1}$ Lensky, I. M. and Rosenfeld, D.: Clouds-AerosolsPrecipitation Satellite Analysis Tool (CAPSAT), Atmos. Chem. Phys. Discuss., to be submitted, 2007.
} 

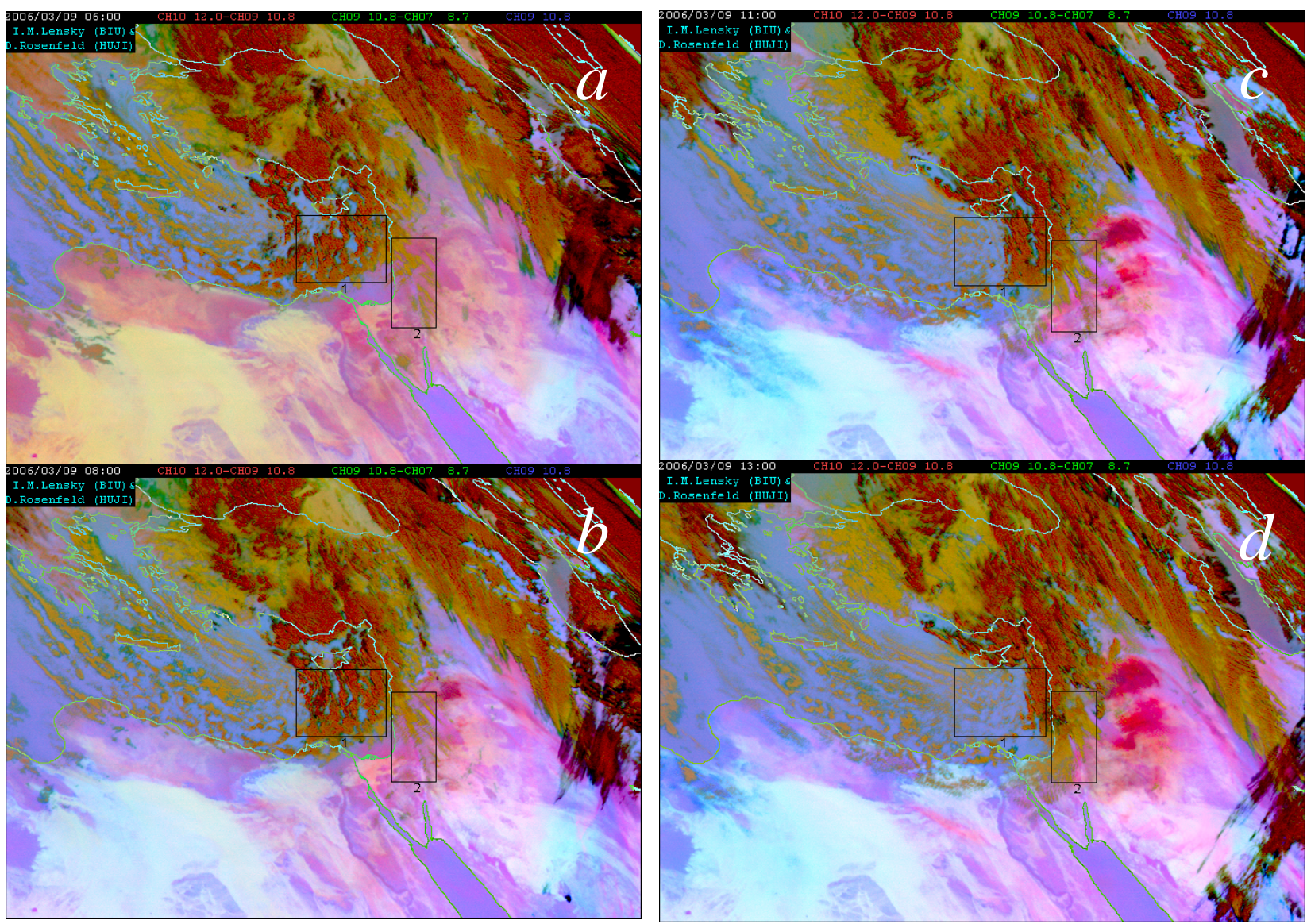

Fig. 4. Clouds and dust over East Mediterranean Sea (area 1) and Israel (area 2). Panel (a) is from 9 March 2006, 06:00 GMT, (b) 08:00 GMT, (c) 11:00 GMT, and (d) 13:00 GMT. In this color scheme clouds are colored in orange and red, and the dust in pink.

d. Dust is actually seen over the eastern part of the delta of the Nile in panel a moving eastward over southeast Mediterranean sea and to the southern part of area 2 in panel b. From this figure one can see that there is much more dust in area 2 than in area 1. Indeed, the time series of the temperatures: $T_{\text {base }}, T_{15}$ and the cloud top temperatures $\left(T_{\text {top }}\right)$ in areas 1 and 2 in Fig. 5 show that the $D_{15}$ parameter is much larger in area 2 than in area 1, indicating that the clouds that were exposed to the dust (in area 2) are more continental (smaller $r_{e}$, larger diffusional growth zones, and larger $D_{15}$ ). Figure 6 shows time series of the temperature of the base and top of the RLT zones: diffusion (orange), coalescence (red), mixed phase (purple) and glaciated (blue), and the temperature of onset of precipitation ( $T_{15}$ - in green) for the same data as in area 1 of this case study. Note that onset of precipitation $\left(T_{15}\right)$ is reached only after coalescence (or mixed phase) are initiated.

The pink colors in Fig. 4 can give a qualitative indication to the existence of dust. A more refined quantitative parameter of the aerosol loading was checked here. The reflectance of sea water in the visible channel $(0.6 \mu \mathrm{m})$ in Clear sky con-

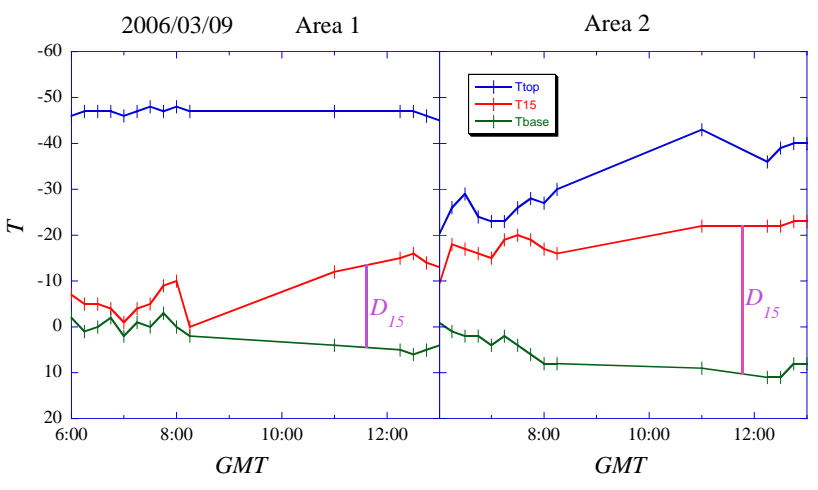

Fig. 5. Time series of the cloud base temperature $\left(T_{\text {base }}\right)$, the temperature of onset of precipitation $\left(T_{15}\right)$, and cloud top temperature ( $T_{\text {top }}$ ), of the clouds in Fig. 4. $D_{15}$ is the temperature difference (depth) between $T_{15}$ and $T_{\text {base }}$.

ditions (aer) is very low (3.5-4\%) and uniform. Over this dark uniform background, any addition of aerosol loading will result in higher visible reflectance. We assume that the 


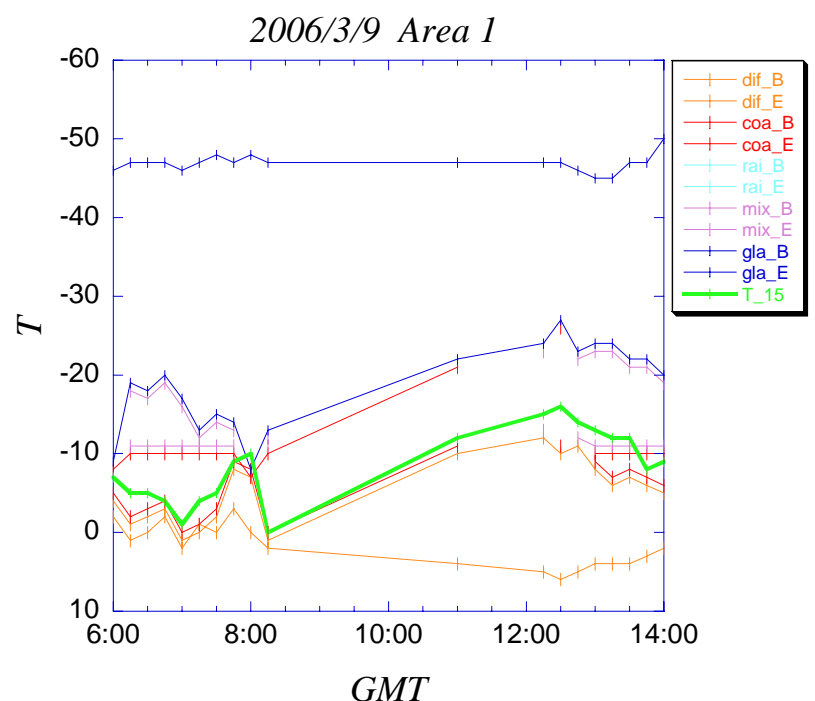

Fig. 6. Time series of the temperature of the base and top of the RLT zones: diffusion (orange), coalescence (red), mixed phase (purple) and glaciated (blue), and the temperature of onset of precipitation $\left(T_{15}\right)$ (green) for the same data as in area 1 of Fig. 5. $T_{15}$ is reached only after coalescence (or mixed phase) is initiated.

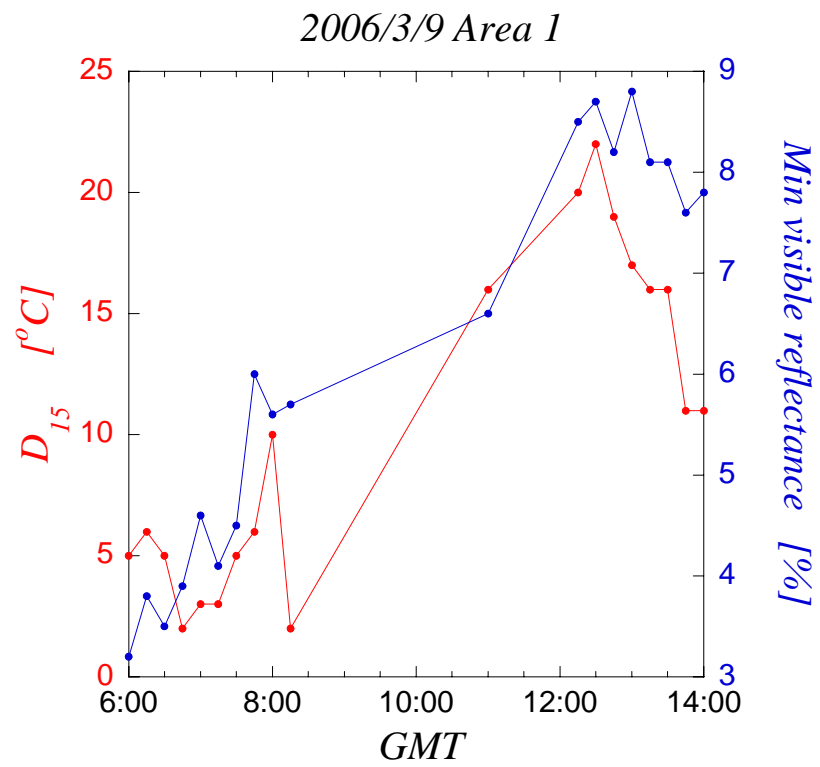

Fig. 7. Time series of $D_{15}$ and the minimal visible $(0.6 \mu \mathrm{m})$ reflectance for the same data as figure 6 . The minimal visible reflectance is used here as a quantitative measure for aerosol loading, and shown here to be highly correlated to $D_{15}$. Also notable is the clouds' response to the aerosol loading.

cloud free minimum visible reflectance in area 1 is correlated with aerosol loading. Figure 7 shows time series of $D_{15}$ and aer in area 1 . These two parameters are highly correlated. Also notable is the quick response of the cloud microphysics to the aerosol loading: in most of the curve it is shorter than the 15 min interval of the MSG data.

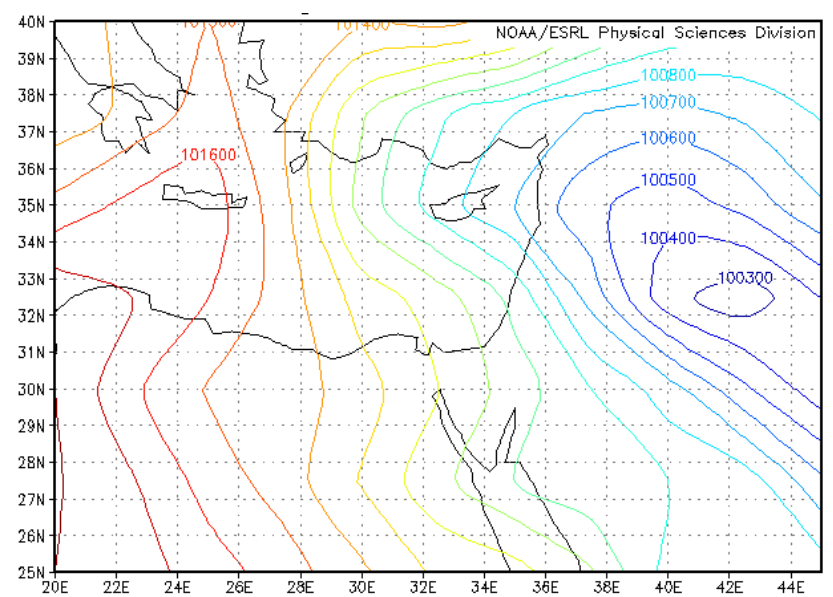

Fig. 8. As Fig. 3, but for 2 April 2006, 12:00 GMT.

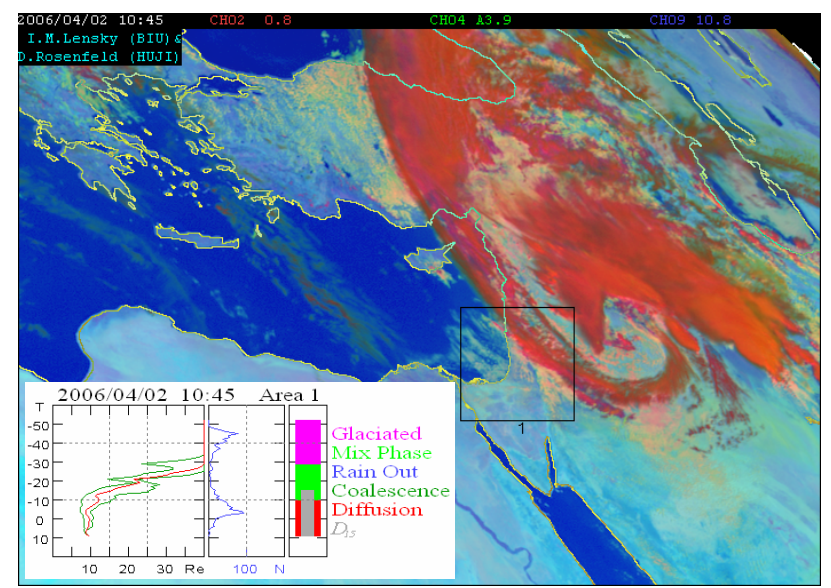

Fig. 9. $T-r_{e}$ plot of Area 1, 2 April 2006, 10:45 GMT; the number of pixels (in blue) in each $1^{\circ} \mathrm{C}$ temperature interval, and the microphysical zones, showing deep diffusional growth zone $\left(\sim 20^{\circ} \mathrm{C}\right)$ with $r_{e}<10 \mu \mathrm{m}$, followed by mixed phase zone with probably coalescence $\left(\sim 20^{\circ} \mathrm{C}\right)$ and glaciation zone $\left(\sim 22^{\circ} \mathrm{C}\right)$. Heavy rains occurred in Wadi Ara region in the northern part of Israel, resulting with severe floods, and record high rain intensity and duration. $D_{15}$ shows extremely continental values of $\sim 25^{\circ} \mathrm{C}$, as those of clouds in heavy smoke (Lensky and Drori, 2007).

In the second case study of 2 April heavy rains occurred in the Wadi Ara region in the northern part of Israel, resulting with severe floods, and record-high rain intensity and duration. Figure 8 shows the Sea level pressure (in Pascal) of 12:00 GMT of this case study. Figure 9 shows $T-r_{e}$ plot of Area 2 of this case study, from 10:45 GMT, and the microphysical zones, showing a deep diffusional growth zone $\left(\sim 20^{\circ} \mathrm{C}\right)$ with $r_{e}<10 \mu \mathrm{m}$, followed by a mixed phase zone $\left(\sim 20^{\circ} \mathrm{C}\right)$. As the slope of the $T-r_{e}$ curve in both coalescence and mixed phase growth may be the same, the RLT takes an arbitrary temperature of $-10^{\circ} \mathrm{C}$, as the limit between these 


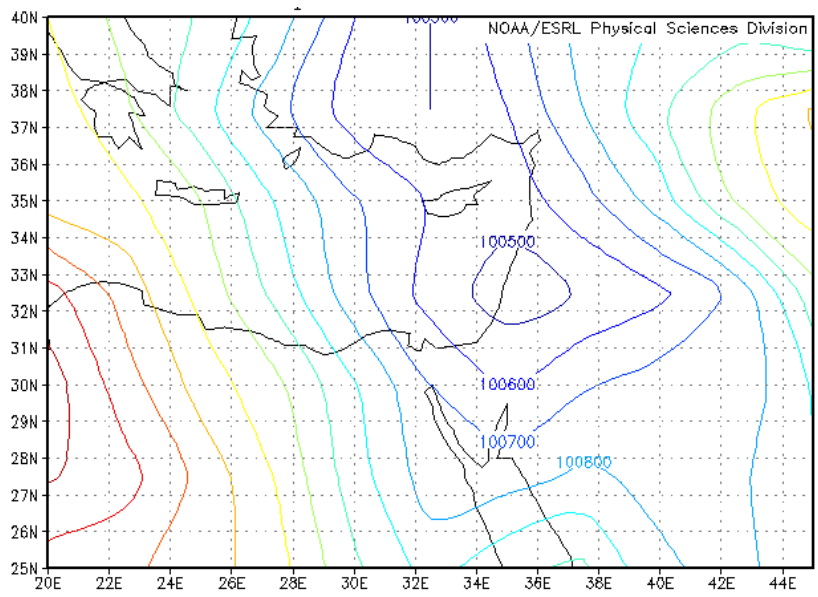

Fig. 10. As Fig. 3, but for 4 April 2006, 12:00 GMT.

two microphysical growth zones. To get a more reliable picture on which of the processes actually exists in that temperature interval in the analyzed area, a spectral analysis on pixel basis (the pixels in that temperature interval) should be carried out. This can be done for example by looking at the ratio between the reflectance in 0.6 and $1.6 \mu \mathrm{m}$ where the larger values will indicate the existence of ice. A glaciation zone of about $22^{\circ} \mathrm{C}$ followed the mixed phase zone. $D_{15}$ shows extremely continental values of about $25^{\circ} \mathrm{C}$, similar to clouds in heavy smoke (Lensky and Drori, 2007).

In the third case study a quickly deepening upper trough formed a surface low over South East Mediterranean during the night between 3 and 4 April. The upper air system continued to develop forming a low over Cyprus on the noon of 4 April, creating an extremely unstable atmosphere over Israel and allowing the development of a super cell in the north. Figure 8 shows the $T-r_{e}$ plot of the data extracted from area 2 on 4 April, 13:00 GMT. The microphysical zones of this area are showing a very deep diffusional growth zone of about $25^{\circ} \mathrm{C}$, followed by a shallow mixed phase zone $\left(\sim 12^{\circ} \mathrm{C}\right)$ and a glaciation zone $\left(\sim 15^{\circ} \mathrm{C}\right)$. Like the case of 4 April, $D_{15}$ shows extremely continental values of about $27^{\circ} \mathrm{C}$, which are typical to clouds in heavy smoke (Lensky and Drori, 2007). A tornado and giant hail followed shortly after in this area.

\section{Summary and conclusions}

Three case studies of severe weather events were shown here. Time series of precipitation formation processes in clouds over sea and land were monitored, as well as the impact of aerosols on these processes. The clouds that were monitored in this study were clouds that passed in two predefined areas. We plan to further elaborate the approach that was demonstrated here by applying a cloud tracking algorithm on the MSG data and then using the RLT microphysical zones and

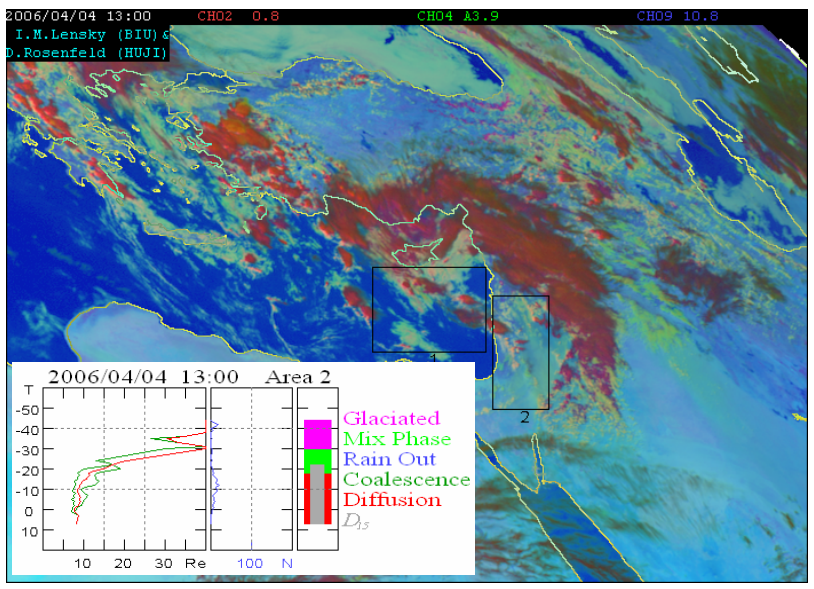

Fig. 11. As Fig, 9 only for 4 April 2006, 13:00 GMT area 2; the microphysical zones show here very deep diffusional growth zone $\left(\sim 25^{\circ} \mathrm{C}\right)$, followed by shallow mixed phase zone $\left(\sim 12^{\circ} \mathrm{C}\right)$ and glaciation zone $\left(\sim 15^{\circ} \mathrm{C}\right) . D_{15}$ shows extremely continental values of $\sim 27^{\circ} \mathrm{C}$, as those of clouds in heavy smoke (Lensky and Drori, 2007). A tornado followed shortly after in this area.

the $D_{15}$ parameter on the individual cloud clusters that are tracked. This can be very beneficial for short predictions as to the nature of clouds coming in and the potential risk for sever storms producing floods or hail from these clouds. To this end we plan to combine the RLT microphysical zones and the $D_{15}$ parameter inferred from the multyspectral MSG data with radar data.

Acknowledgements. The authors thank Yoav Levy and Yoni Pikarsky for the valuable discussion, and to EUMETSAT for the MSG data.

Edited by: P. Alpert, H. Saaroni, and E. Heifetz Reviewed by: two anonymous referees

\section{References}

Freud, E., Rosenfeld, D., Andreae, M. O., Costa, A. A., and Artaxo, P.: Robust relations between $\mathrm{CCN}$ and the vertical evolution of cloud drop size distribution in deep convective clouds, Atmos. Chem. Phys. Discuss., 5, 10 155-10 195, 2005.

Kalnay, E., Kanamitsu, M., Kistler, R., Collins, W., Deaven, D., Gandin, L., Iredell, M., Saha, S., White, G., Woollen, J., Zhu, Y., Chelliah, M., Ebisuzaki, W., Higgins, W., Janowiak, J., Mo, K. C., Ropelewski, C., Wang,J., Leetmaa, A., Reynolds, R., Jenne, R., and Joseph, D.: The NCEP/NCAR 40-Year Reanalysis Project, B. Am. Meteor. Soc., 77, 437-471, 1996.

Kistler, R., Kalnay, E., Collins, W., Saha, S., White, G., Woollen, J., Chelliah, M., Ebisuzaki, W., Kanamitsu, M., Kousky, V., van den Dool, H., Jenne, R., and Fiorino, M.: The NCEP/NCAR 50year reanalysis: Monthly means CD-ROM and documentation, B. Am. Meteor. Soc., 82, 247-267, 2001.

Lensky, I. M. and Rosenfeld, D.: Estimation of precipitation area and rain intensity based on the microphysical properties retrieved 
from NOAA AVHRR data, J. Appl. Meteorol., 36, 234-242, 1997.

Lensky, I. M. and Rosenfeld, D.: The time-space exchangeability of satellite retrieved relations between cloud top temperature and particle effective radius, Atmos. Chem. Phys., 6, 2887-2894, 2006,

http://www.atmos-chem-phys.net/6/2887/2006/.

Lensky, I. M. and Drori, R.: A Satellite Based Parameter to Monitor the Aerosol Impact on Convective Clouds, J. Appl. Meteorol. Clim., 45, 660-666, 2007.

Rosenfeld, D. and Lensky, I. M.: Satellite-based insights into precipitation formation processes in continental and maritime convective clouds, B. Am. Meteor. Soc., 79, 2457-2476, 1998.

Rosenfeld, D.: TRMM observed first direct evidence of smoke from forest fires inhibiting rainfall, Geophys. Res. Lett., 26, 31053108, 1999.

Rosenfeld, D.: Suppression of rain and snow by urban and industrial air pollution, Science, 287, 1793-1796, 2000.

Rosenfeld, D., Rudich, Y., and Lahav, R.: Desert dust suppressing: A possible desertification feedback loop, Proc. Natl. Acad. Sci. USA, 98, 5975-5980, 2001.

Rosenfeld, D., Lahav, R., Khain, A. P., and Pinsky, M.: The role of sea-spray in cleansing air pollution over ocean via cloud processes, Science, 297, 1667-1670, 2002.

Rosenfeld, D., Cattani, E., Melani, S., and Levizzani, V.: Considerations on daylight operation of $1.6 \mu \mathrm{m}$ vs $3.7 \mu \mathrm{m}$ channel on NOAA and METOP Satellites, B. Am. Meteor. Soc., 85, 873$881,2004$.

Rosenfeld, D. and Woodley, W. L.: Closing the 50-year circle: From cloud seeding to space and back to climate change through precipitation physics, Chapter 6, in: Cloud Systems, Hurricanes, and the Tropical Rainfall Measuring Mission (TRMM), edited by: Wei-Kuo Tao and Adler, R., Meteorological Monographs 51, AMS, 234 pp., 59-80, 2003.
Rosenfeld, D. and Woodley, W. L.: Pollution and Clouds. Physics World, Institute of Physics Publishing LTD, Dirac House, Temple Back, Bristol BS1 6BE, UK, February 2001, 33-37, 2001.

Rosenfeld D., Lensky, I. M., Peterson, J., and Gingis, A.: Potential impacts of air pollution aerosols on precipitation in Australia, Clean Air and Environmental Quality, 41, 43-49, 2006.

Ramanathan, V., Crutzen, P. J., Kiehl, J. T., and Rosenfeld, D.: Aerosols, Climate and the Hydrological Cycle, Science, 294, 2119-2124, 2001.

Rudich, Y., Rosenfeld, D., and Khersonsky, O.: Treating clouds with a grain of salt, Geophys. Res. Lett., 29(22), 2060, doi:10.1029/2002GL016055, 2002.

Rudich, Y., Sagi, A., and Rosenfeld, D.: Influence of the Kuwait oil fires plume (1991) on the microphysical development of clouds, J. Geophys. Res., 108(D15), 4478, doi:10.1029/2003JD003472, 2003.

Schmetz, J., Pili, P., Tjemkes, S., Just, D., Kerkmann, J., Rota, S., and Ratier, A.: An Introduction to Meteosat Second Generation (MSG), B. Am. Meteor. Soc., 83, 977-992, 2002.

Tupper, A., Oswalt, J. S., and Rosenfeld, D.: Satellite and radar analysis of the 'volcanic' thunderstorms at Mt Pinatubo, Philippines, 1991, J. Geophys. Res., 110, D09204, doi:10.1029/2004JD005499, 2004.

Williams, E., Rosenfeld, D., and Madden, M.: Contrasting convective regimes over the Amazon: Implications for cloud electrification, J. Geophys. Res., 107(D20), 8082, doi:10.1029/2001JD000380, 2002.

Woodley, W. L., Rosenfeld, D., and Strautins, A.: Identification of a seeding signature in Texas using multi-spectral satellite imagery, J. Wea. Mod., 32, 37-52, 2000. 